\title{
Comparison of lightning activity and radar-retrieved microphysical properties in EULINOX storms
}

\author{
Thorsten Fehr*, Nikolai Dotzek, Hartmut Höller \\ Institut für Physik der Atmosphäre, Deutsches Zentrum für Luft- und Raumfahrt, Oberpfaffenhofen, \\ 82234 Wessling, Germany
}

Received 10 November 2003; accepted 1 September 2004

\begin{abstract}
A combined analysis of microphysical thunderstorm properties derived by C-band polarimetric Doppler radar measurements and lightning observations from two ground-based systems are presented. Three types of storms, a multicell, a supercell, and a squall line, that were observed during the European Lightning Nitrogen Oxides project (EULINOX) are investigated. Correlations are sought between the mass of rain, graupel, hail, and snow derived form radar observations at different height levels and the electrical activity, represented either by cloud-to-ground or intracloud flashes. These relationships are explained by connecting the radar-derived properties with the non-inductive charging process. For the multicell and the supercell storm, the lightning activity can be linearly correlated to both the hydrometeor total mass and class specific mass in the upper part of the storm. It is shown that the fractions of graupel and hail above the $-20{ }^{\circ} \mathrm{C}$-level in these storms positively correlate with the intracloud flash activity in the supercell, and negatively for the cloud-to-ground lightning frequency in the multicell. No such relation can be established for the squall line, indicating that the convective organization plays a crucial role in the lightning development. The analysis of the masses in the different storms shows that lightning activity cannot be parameterized by total mass alone, other parameters have to be identified. The results provide important information for all lightning studies that rely on bulk properties of thunderstorms, e.g., the parameterization of lightning in mesoscale models or the nowcasting of lightning by radar.
\end{abstract}

(C) 2005 Elsevier B.V. All rights reserved.

Keywords: Lightning; Thunderstorm type; Polarimetric radar

\footnotetext{
* Corresponding author.

E-mail address: thorsten.fehr@dlr.de (T. Fehr).
} 


\section{Introduction}

The study of lightning-related phenomena with mesoscale model simulations requires a computationally efficient and yet realistic representation of the electrical activity in thunderstorms. In general, there are two approaches: (1) Simulation of the charge development by collision processes and transport of the hydrometeors, followed by the initiation of lightning according to the electrical field (e.g., MacGorman et al., 2001; Molinié et al., 2002; Mansell et al., 2002) and (2) the parameterization of the electrical activity using bulk microphysical and dynamical model variables alone (e.g., Price and Rind, 1992, 1993; Allen and Pickering, 2002; Kurz and Grewe, 2002). For storm- and mesoscale problems focusing on the effects of total lightning activity, e.g., in the study of lightning-induced nitrogen oxides (Pickering et al., 1998; Fehr et al., 2004), the explicit simulation of charge is very expensive numerically or not feasible due to the limited degree of microphysics in the models. Therefore efficient and realistic bulk parameterizations have to be developed.

In a dimensional analysis, Baker et al. (1995) conclude that the lightning frequency $f$ in a storm is proportional to the sixth power of the updraft velocity $w$. Based on observations, Price and Rind $(1992,1993)$ find the lightning frequency to be proportional to $w^{4.55}$, as well as a function relating the ratio of intracloud (IC) to cloud-to-ground (CG) flashes to the cloud depth above the freezing level. Their results were applied and adapted in various model studies on different scales (e.g., Pickering et al., 1998; Stockwell et al., 1999; DeCaria et al., 2000). On the cloud scale, however, this parameterization can lead to an unrealistic threefold overestimation of the lightning activity (Fehr, 2000; Fehr et al., 2004).

According to the non-inductive charging mechanism, charge separation in storms depends on the collision and growth properties of ice particles (Takahashi, 1978; Saunders, 1993). Thus, a possible extension to the parameterization of lightning by the updraft velocity alone is the additional use of the hydrometeor distribution. Polarimetric radar measurements can be exploited for the identification and quantification of different hydrometeor classes (e.g., Höller et al., 1994; Höller, 1995; Straka et al., 2000). If combined with lightning observations, this data can be used to correlate the bulk microphysical development with the electrical evolution of the storm (Dotzek et al., 2001). The main target of this study is to test whether bulk microphysics can be used for the parameterization of lightning and to identify significant correlations to be used for new parameterizations that hold for the lightning evolution in the early, mature, and decaying stages of the storm.

During the field campaign of the European Lightning Nitrogen Oxides Experiment (EULINOX, Höller and Schumann, 2000) in southern Germany, thunderstorms were intensively investigated with radar and lightning detection systems. This study will focus on three EULINOX thunderstorms that represent different levels of convective organization, size, and intensity typically encountered at mid-latitudes: a multicell storm, a squall line, and a supercell storm.

Section 2 will present the main observation systems and the general methodology of the analysis. It is followed by the summary of the observations for the individual storms in Section 3. The results are discussed in Section 4 and the conclusions are summarized in Section 5 . 


\section{Lightning and radar data}

The lightning activity in the main observation area of the EULINOX campaign (Fig. 1) was monitored by two different systems. The BLIDS (Blitz Informationsdienst von Siemens) system is a commercial lightning detection network that is operated by the Siemens AG and completely covers Germany and Switzerland. In many respects it is comparable to the U.S. National Lightning Detection Network, NLDN (Cummins et al., 1998). The system is designed for the detection of the impact point of CG return stokes in the VLF/LF band. Single strokes can be horizontally localized with an accuracy of $500 \mathrm{~m}$ or better. For the period of the EULINOX campaign, the ONERA (Office National d'Etudes et de Recherches Aérospatiales) provided an interferometric lightning mapper (ITF, Defer, 1999). The system consists of two VHF receivers tuned to $114 \mathrm{MHz}$ with a narrow bandwidth of $1 \mathrm{MHz}$. The interferometric data analysis allows a three-dimensional reconstruction of the fast streamer processes both from CG and IC lightning (Mazur et al., 1997; Defer et al., 2001). The resolution of the system is a few hundred meters, and a single flash can consist of up to a few thousand individual signals. The ITF can monitor the threedimensional total lightning activity within approximately $75 \mathrm{~km}$ around the radar as shown in Fig. 1. In this study, only the horizontal positioning of the ITF flashes is exploited.

CG flash data derived from BLIDS and total activity identified with the ITF lightning observations are averaged over 5 min intervals, smoothing fast changes in the flash frequency, while still representing the lightning activity for the convective state of the storm. A further description of the interferometric system as well as a comprehensive comparison between the BLIDS and the ITF detection efficiencies during EULINOX was

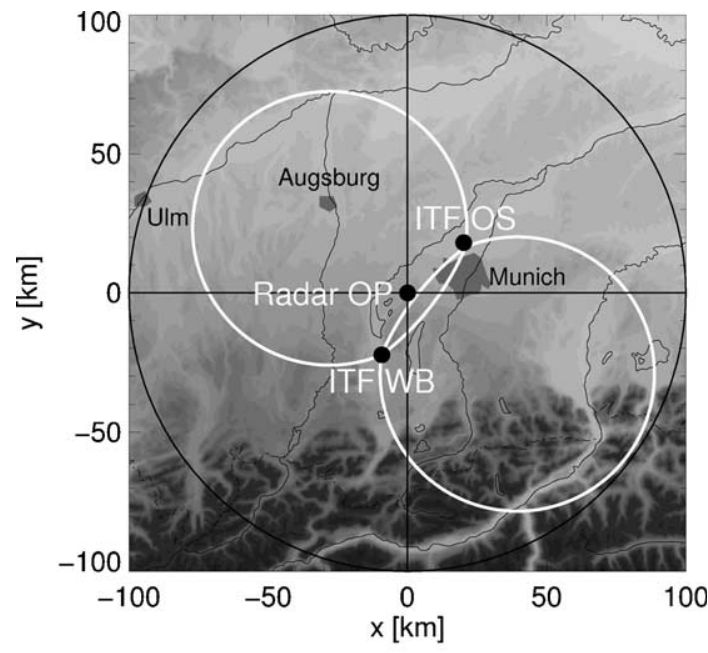

SOA, Terrain $[\mathrm{km}]$

$\begin{array}{lllll}0.5 & 1.0 & 1.5 & 2.0 & 2.5\end{array}$

Fig. 1. Special observation area for the study: The analysis is confined within the $100 \mathrm{~km}$ range (black range ring) around the POLDIRAD radar (Radar OP). Only those ONERA ITF flashes are used that were detected within the white range rings, restricted by the two antennas at Wielenbach (ITF WB) and Oberschleissheim (ITF OS). 
presented by Théry (2001). A similar comparison between the NLDN and the ITF was presented by Lang (1997) and Defer et al. (2001) for the STERAO-A experiment (Dye et al., 2000).

The development of the storms was monitored with the C-band polarization diversity Doppler radar POLDIRAD (Schroth et al., 1988) positioned at Oberpfaffenhofen, cf. Fig. 1. POLDIRAD is operated by the DLR (Deutsches Zentrum für Luft- und Raumfahrt). The polarimetric parameters can be used to identify different particle classes inside clouds. Höller et al. (1994) have developed a classification scheme based on radar reflectivity factor $Z$, differential reflectivity $Z_{\mathrm{DR}}$, and linear depolarization ratio LDR. It is capable to distinguish between 11 hydrometeor classes: Small raindrops, large raindrops, snow/ graupel (dry, small), graupel, and six different hail classes. In addition, contamination of the radar data from multi-body scattering (hail spikes) and differential attenuation (propagation effects) are removed.

In a further extension of the original scheme, Höller (1995) developed a method to derive mass concentrations for different hydrometeor types inside a thunderstorm. The hydrometeor classes identified using the $Z_{\mathrm{DR}}$ and LDR measurements are grouped into four basic classes: rain, snow/graupel, graupel, and hail. The reflectivity factor is used to determine the water or ice content $\mathrm{M}$ by applying empirical relations to $Z$ and the precipitation rate $R$. The general form of the empirical equations is:

$$
Z=a \cdot R^{b}, M=c \cdot R^{d},
$$

which can be summarized to give:

$$
M=\alpha \cdot Z^{\beta} .
$$

The parameters $\alpha$ and $\beta$ depend on the hydrometeor class and the type of precipitation system under investigation. As given together with their corresponding references in Table 1, the values used for this study were derived from thunderstorm observations. In mixed-phase regions, the water and ice fractions are assumed to depend linearly on LDR. High LDR values indicate the predominance of hail. A similar relation is supposed to describe the graupel-hail and snow-graupel transitions. Rain regions are assumed to be confined to reflectivity values up to about $55 \mathrm{dBZ}$. Even if LDR and $Z_{\mathrm{DR}}$ are still consistent with pure rain the very high reflectivity values do indicate the presence of some hailstones. Otherwise extremely high liquid water contents would be analyzed from the $Z-M$ relations.

An example for the application of this scheme is presented in Fig. 2, where a vertical cross section through the 21 July 1998 supercell storm, that will be further analyzed in the

Table 1

Coefficients used for the $Z-M$ relation in Eq. (2) with $Z$ in $\mathrm{mm}^{6} \mathrm{~m}^{-3}$ and $M$ in $\mathrm{g} \mathrm{m}^{3}$

\begin{tabular}{llll}
\hline Hydrometeor class & $\alpha$ & $\beta$ & Reference \\
\hline Rain & $0.91 \times 10^{-3}$ & 0.70 & Sekhon and Srivastava (1971) \\
Snow & $5.56 \times 10^{-3}$ & 0.46 & Yagi and Uyeda (1980) \\
Graupel & $2.44 \times 10^{-3}$ & 0.56 & Yagi and Uyeda (1980) \\
Hail & $0.19 \times 10^{-3}$ & 0.67 & Federer and Waldvogel (1975) \\
\hline
\end{tabular}



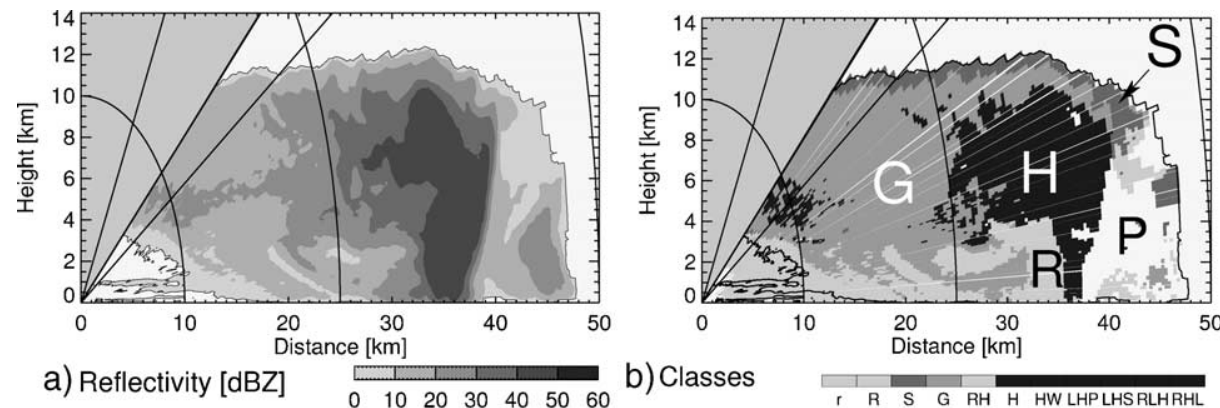

a) Reflectivity [dBZ]
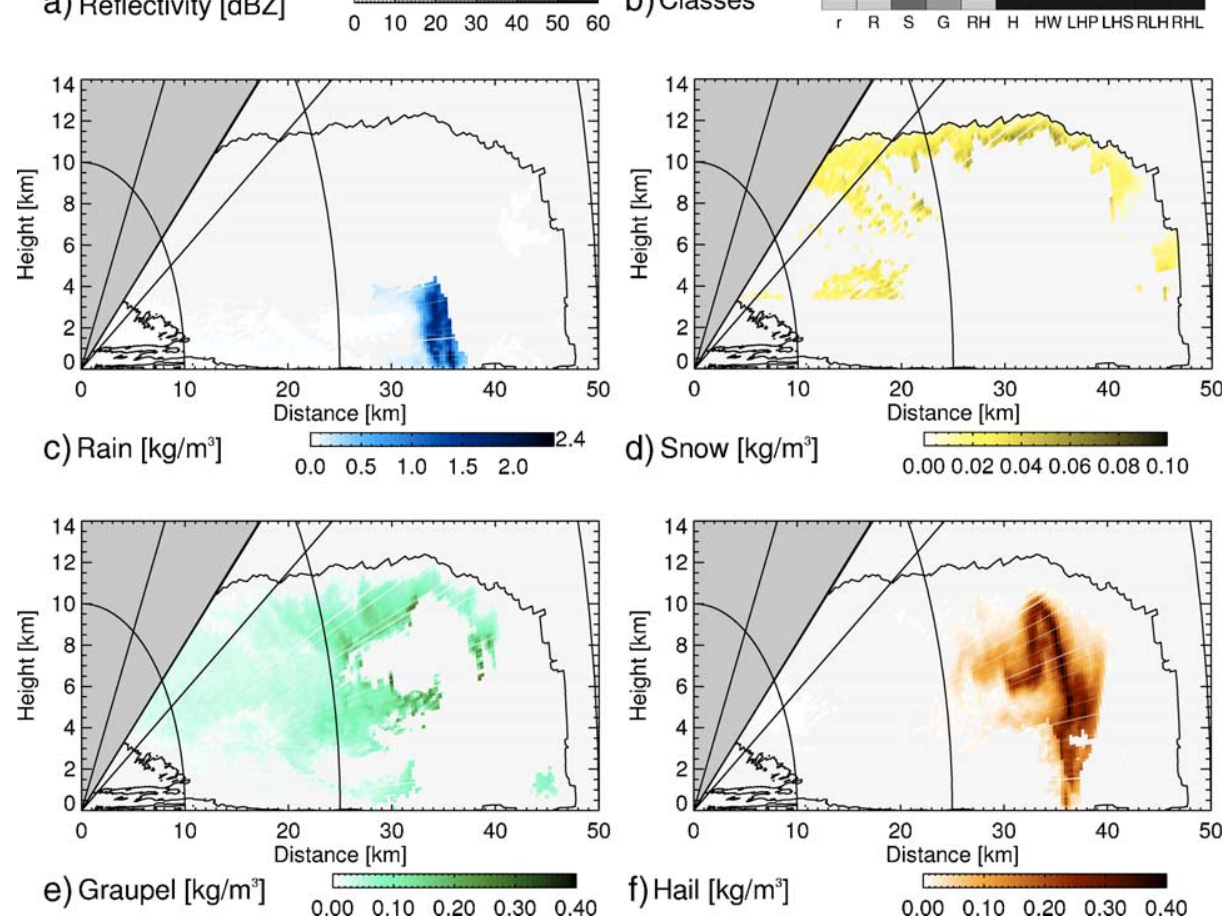

Fig. 2. Vertical cross section through the 21 July 1998 supercell core at 1752 UTC. (a) Radar reflectivity. (b) Distribution of hydrometeor classes, rain $(\mathrm{R})$, graupel $(\mathrm{G})$, hail $(\mathrm{H})$, and snow $(\mathrm{S})$, as well as the region that was discarded due to propagation effects (P). (c) Rain water content, (d) snow content, (e) graupel content, and (f) hail content.

following sections, is shown. Note that in convective storms the snow/graupel class consists predominately of small, dry graupel. In order to provide an optimum characterization of the complete storm only radar volume scans are used for the particle classification.

For the analysis of height-dependent processes, the convective systems considered in this study are vertically separated in three different layers: (1) the region between the $0{ }^{\circ} \mathrm{C}$ isotherm ("base layer") and the ground, (2) the mid-level region between the $0{ }^{\circ} \mathrm{C}$ and the $-20{ }^{\circ} \mathrm{C}$ isotherm, and (3) the upper cloud region above the $-20{ }^{\circ} \mathrm{C}$ isotherm, including the anvil and the upper part of the storm core. The corresponding height values for the 
temperature levels are taken from the 1200 UTC radiosonde observations at Oberschleissheim (Fig. 1). The resulting altitudes above sea level are $3.6 \mathrm{~km}, 4.0 \mathrm{~km}$, and $3.7 \mathrm{~km}$ for the $0{ }^{\circ} \mathrm{C}$ isotherm, and $6.8 \mathrm{~km}, 7.2 \mathrm{~km}$, and $6.8 \mathrm{~km}$ for the $-20{ }^{\circ} \mathrm{C}$ isotherm of the multicell, supercell, and squall line, respectively.

The layers were chosen according to the simplified electrical tripole-model of thunderstorms that result from the basic non-inductive charging process (e.g., Saunders, 1993; Stolzenburg et al., 1998). The charge generation processes are mainly concentrated in the lower part of the mid-level layer where charge is generated by graupel-ice collisions in the presence of supercooled liquid water. Following the simplified tripole model, which is a reasonable approximation for severe storms (Marshall et al., 1995), the negative charge center would be in the mid-level layer, while the positive charge is located in the upper level. However, also an inversion of the polarity can be observed, where the lower main charge center is positive (Lang and Rutledge, 2002).

The lightning frequencies will be correlated to both the radar derived mass of the individual hydrometeor classes and the relative amount of a given hydrometeor class to the total mass in the three levels. The mass itself is a rough measure of the particle density, while the relative amount of the different classes reflects the dynamics of the storm. In addition, this mass fraction is less sensitive to changes in the sample volume as compared to the total mass. Thus, this indicator also allows the comparison of storms that differ in size where the total mass can vary by more than an order of magnitude, while the electrical activity is comparable. Nevertheless, only those radar volume scans are used that do include a major fraction of the storm, and in particular the convective core.

\section{Results from combining radar and lightning observations}

Three convective systems that differ significantly in their dynamical organization and lightning characteristics are analyzed: a multicell complex, a supercell, and a squall line with a well-defined leading edge (Fig. 3). All storms were long-lived and remained in the main observation area for 2 to $4 \mathrm{~h}$. Due to the limited ITF field of view, a complete IC and CG lightning characterization is only possible for the supercell, while for the other systems the focus is on the CG lightning activity as observed by the BLIDS system.

\subsection{June 1998: multicell storm}

The first system is a multicell storm that formed $80 \mathrm{~km}$ west of the radar in the afternoon (1445 UTC) ahead of a cold front approaching from the northwest. The system showed little internal organization of the individual cells (Fig. 3a). Both radar and BLIDS observed the thunderstorm complex until 1830 UTC. During this period, the storm was crossing the ITF area between 1520 and 1715 UTC.

The total lightning activity of the multicell (Fig. 4a) is characterized by a rapid increase to almost 60 flashes per minute within the first $40 \mathrm{~min}$ of the storm. Note that the storm enters the ITF area at 1520 UTC. After reaching this maximum, the lightning frequency decreases to a minimum of a few flashes per minute before converging to about $10 \mathrm{~min}^{-1}$. This value remains approximately constant until the multicell starts to leave the ITF field 


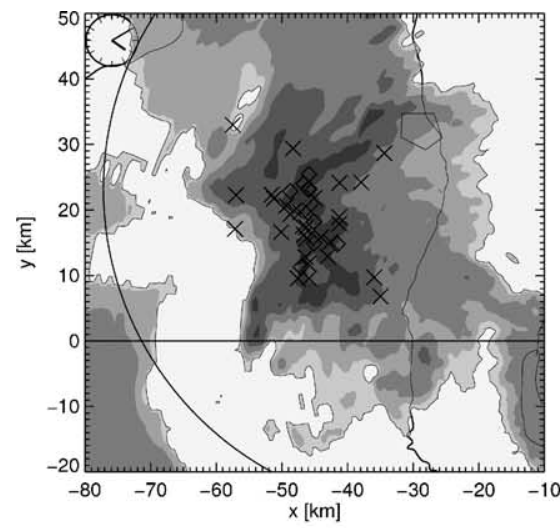

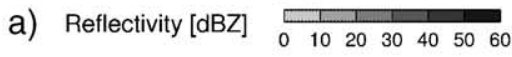

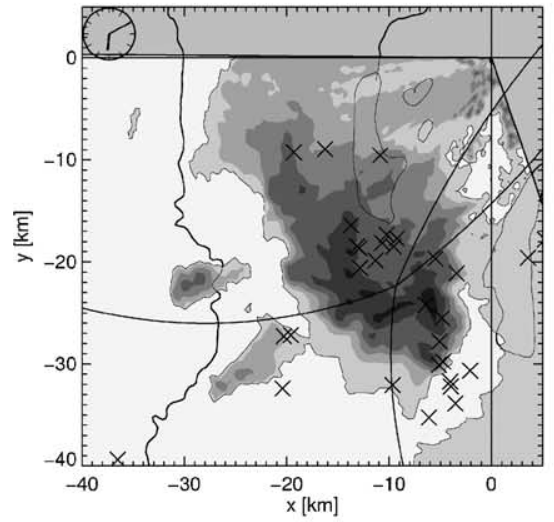

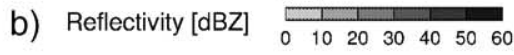

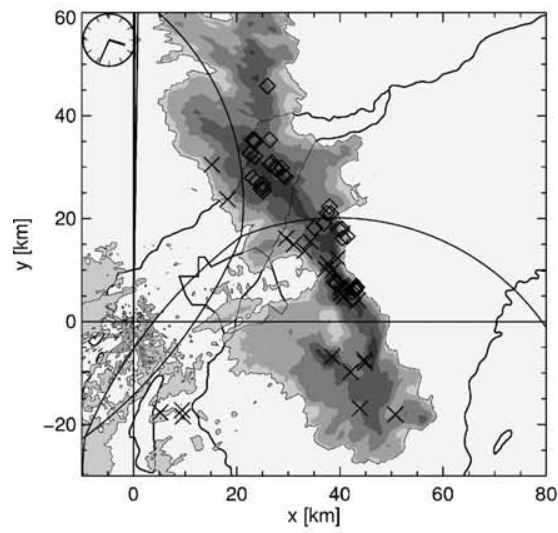

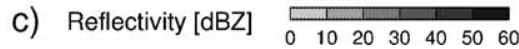

Fig. 3. Horizontal radar scans at $1^{\circ}$ elevation: (a) Multicell at 1600 UTC, (b) supercell at 1810 UTC, and (c) squall line at 1531 UTC. The position of LPATS $(\diamond)$ and ITF $(\times)$ flashes within a 1 min interval around the scan time are indicated. 

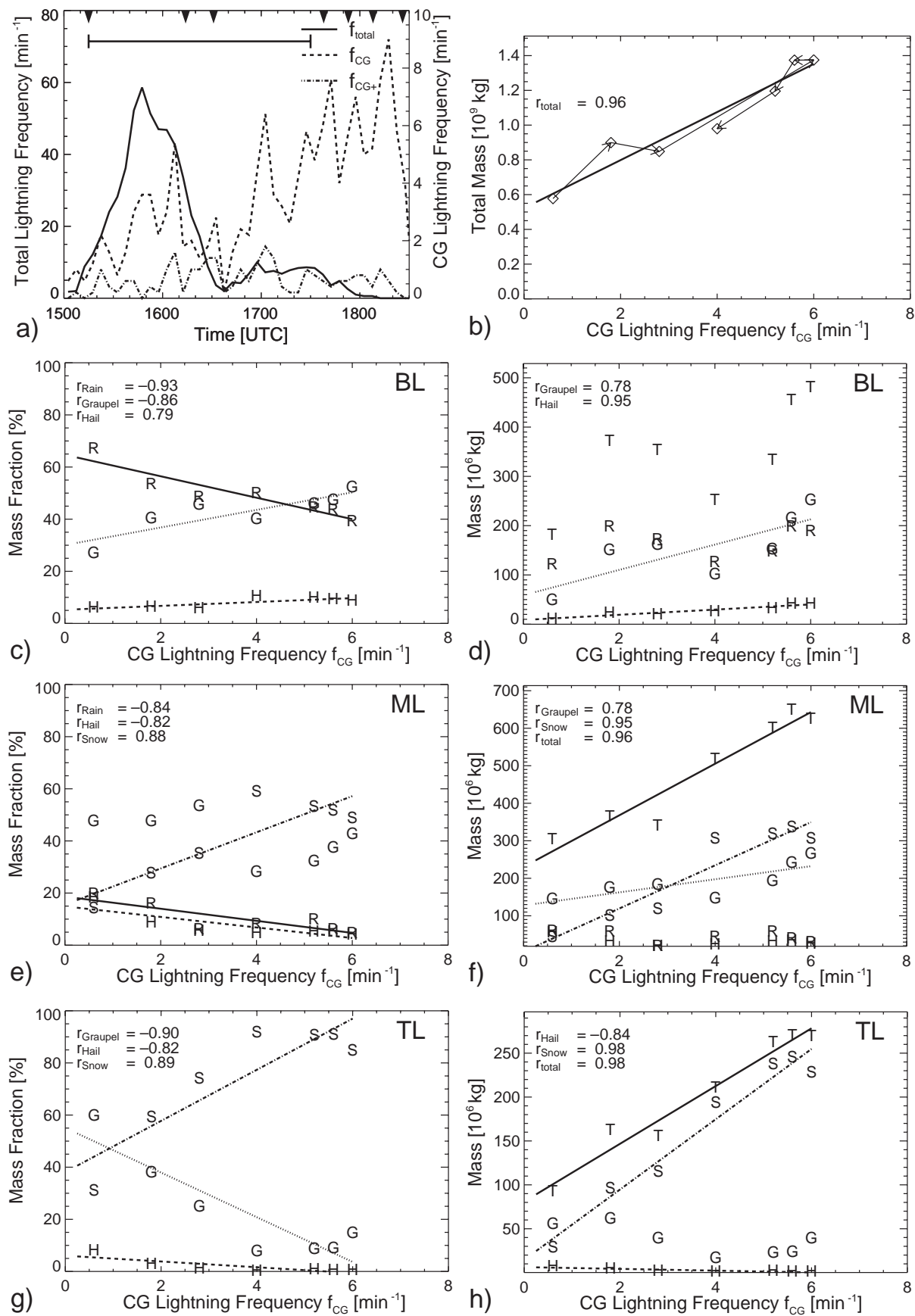
of view at around 1715 UTC. The CG lightning activity on the other hand is characterized by approximately nine distinct maxima, where the maximum values of the CG flash frequency increase from 1 to 9 flashes per minute during the whole observation period. For the complete lifetime of the multicell the total number of $\mathrm{CG}$ flashes recorded by the BLIDS system reached 5100, of which 300 were positive lightning $(\mathrm{CG}+)$. During the $2 \mathrm{~h}$ that the system was located inside or close to the ITF observation area, a total of 3100 flashes were recorded by the ITF system for the multicell. The observations indicate that after 1630 UTC until the storm is leaving the ITF area, CG lightning constitutes a large fraction of the total lightning activity. After this period, however, there is no information on the total lightning activity in the storm.

Seven volume scans with polarimetric parameters were recorded for the multicell. The scans are not spaced equally in time but biased to the end of the observation period with only two volume scans while the storm is inside the ITF area. Therefore, in order to have a consistent description of the lightning and bulk microphysical evolution of the storm for a considerable number of volume scans, the analysis focuses on CG lightning as a measure for the electrical activity, with the restriction that CG flashes do only represent a part of the overall lightning development.

The total mass and the mass fraction of the particle classes and the corresponding CG lightning frequency are presented in Fig. 4(b-h). For the base layer, the CG lightning activity increases with decreasing rain fraction (Fig. 4c). On the other hand, the frequency increases with a growing fraction of graupel, however, not as well correlated as in the case of rain. There is little sensitivity of the CG lightning activity to the hail fraction, constituting a $5-10 \%$ contribution to the total mass during the observation period. Using linear regression, the dependence of the lightning frequency $f_{\mathrm{CG}}$, in $\mathrm{min}^{-1}$ to the rain and graupel mass fractions $F$ in $\%$ is:

$$
\begin{aligned}
& f_{\mathrm{CG}}=-0.24 F_{\text {rain }}+16\left(r_{\text {rain }}=-0.93\right), \\
& f_{\mathrm{CG}}=0.30 F_{\text {graupel }}-8.9\left(r_{\text {graupel }}=0.87\right),
\end{aligned}
$$

with

$$
F_{i}=\frac{M_{i}}{\sum_{i} M_{i}}, i \in\{\text { rain, snow, graupel, hail }\} .
$$

Here, $r$ denotes the linear correlation coefficient and $M$ the mass of the hydrometeor class in the level. Considering the total mass in the base layer (Fig. 4d), the CG lightning activity shows a positive correlation with the total mass. However, there is a significant scatter in the data and no direct linear relation can be established. On the other hand, for

Fig. 4. Lightning and masses for the multicell: (a) Total, CG (negative and positive), and positive $\mathrm{CG}(\mathrm{CG}+$ ) lightning frequency averaged over $5 \mathrm{~min}$, time of radar volume scans is marked on the upper time-axis, the horizontal bar indicates when the storm is observed by the ITF system. (b) Total mass derived for the complete storm versus CG lightning frequency, the arrows indicate the time sequence of the radar scans. (c-h) Scatter plots of the CG lightning frequency and the mass fraction of rain (R), graupel (G), snow (S), and hail (H) in the (c) base layer (BL), (e) mid-level (ML), and (g) top-level (TL) of the storm. (d), (f), (h) same as (c), (e), (g) but for the mass of the hydrometeor classes and the total mass of all hydrometeors $(\mathrm{T})$. 
hail and, to a lesser extent, graupel there are some reasonable linear relationships between the CG lightning frequency and the mass of the hydrometer class:

$$
\begin{aligned}
& f_{\mathrm{CG}}=0.94 \times 10^{-6} M_{\text {hail }}-5.3\left(r_{\text {hail }}=0.95\right), \\
& f_{\mathrm{CG}}=0.78 \times 10^{-6} M_{\text {graupel }}-25\left(r_{\text {graupel }}=0.78\right),
\end{aligned}
$$

where $M$ denotes the total mass found in the layer in $\mathrm{kg}$.

At mid-level of the storm, between the $0{ }^{\circ} \mathrm{C}$ and $-20{ }^{\circ} \mathrm{C}$ isotherm, the $\mathrm{CG}$ lightning activity increases with a growing snow fraction (Fig. 4e), giving rise to a reasonable positive correlation with a linear correlation coefficient of 0.88 . At the same time, the $\mathrm{CG}$ flash frequency decreases with increasing rain and hail fraction, while there is no definite trend for the correlation of the CG lightning activity with graupel. In case of the masses at mid-level (Fig. 4f), the data exhibit a strong correlation both for the total mass and the mass of snow with the CG lightning frequency:

$$
\begin{aligned}
& f_{\mathrm{CG}}=0.015 \times 10^{-6} M_{\text {total }}-3.4\left(r_{\text {total }}=0.96\right), \\
& f_{\mathrm{CG}}=0.017 \times 10^{-6} M_{\text {snow }}-0.078\left(r_{\text {snow }}=0.95\right) .
\end{aligned}
$$

To a lesser extent, a positive linear correlation of the CG lightning activity to the mass of graupel can be established, while compared to the mass fraction no such relationship can be found for either hail or rain.

A good correlation follows for the mass fractions of snow and graupel in the upper region above $-20{ }^{\circ} \mathrm{C}$ and the $\mathrm{CG}$ lightning activity (Fig. $4 \mathrm{~g}$ ). The $\mathrm{CG}$ flash rate grows strongly and in an almost linear fashion with an increasing (decreasing) snow (graupel) fraction:

$$
\begin{aligned}
& f_{\mathrm{CG}}=-0.12 F_{\text {graupel }}+6.4\left(r_{\text {graupel }}=0.90\right), \\
& f_{\mathrm{CG}}=0.10 F_{\text {snow }}-3.9\left(r_{\text {snow }}=0.89\right) .
\end{aligned}
$$

The largest value of the linear correlation coefficient in the case of the multicell can be found relating CG flash frequency to either total mass or to mass of snow in the top-level:

$$
\begin{aligned}
& f_{\mathrm{CG}}=0.030 \times 10^{-6} M_{\text {total }}-2.5\left(r_{\text {total }}=0.98\right), \\
& f_{\mathrm{CG}}=0.025 \times 10^{-6} M_{\text {snow }}-40\left(r_{\text {snow }}=0.98\right) .
\end{aligned}
$$

Due to the fact that all volume scans considered in the case of the multicell completely cover the storm from top to bottom, the total mass of the storm can be used for the correlation with the CG lightning activity. Fig. $4 \mathrm{~b}$ presents this linear correlation for the thunderstorm:

$$
f_{\mathrm{CG}}=3.8 \times 10^{-6} M_{\mathrm{total}}-7.2\left(r_{\mathrm{total}}=0.96\right) \text {. }
$$




\subsection{August 1998: squall line}

The second system under consideration is a squall line that crossed the main observation area from southwest to northeast between 1400 and 1730 UTC. The lateral extent varied from 60 to over $100 \mathrm{~km}$ along the leading edge. The convective system was well inside the ITF area between 1415 and 1530 UTC. During this period, 70\% of the total lightning activity were $C G$ flashes with a maximum value of $20 \mathrm{~min}^{-1}$ (Fig. 5a). Before leaving the ITF area, the total flash frequency exceeded $30 \mathrm{~min}^{-1}$. However it is not clear from the data whether this was a short burst or the beginning of a longer period of elevated IC flash activity. After leaving the ITF area, the CG lightning frequency remains at about $22 \mathrm{~min}^{-1}$ until a sudden decay in activity at 1730 UTC. Due to the large extent of the squall line, the ITF system only significantly covers the storm during less than half the radar observation period. However, during the time when the squall line was observed by both lightning detection systems, the CG flash frequency restricted to the ITF lobes follows the general tendencies in total activity (Fig. 5b). This provides some confidence to assume that the CG lightning activity is a reasonable indicator for the electrical activity also during the mature stage of the storm. Thus, the analysis focuses on CG lightning.

A total of 14 volume scans are available for the analysis of the storm that are welldistributed over the observation time frame. Due to the fact that the squall line was passing overhead the radar and that the storm was at the outer limits of the main observation area during the late mature and decaying stage, not all volume scans covered every height level. As a result, the radar analysis for the base layer is more biased towards the early stage and for the top-level towards the late mature stage.

With the exception of hail in the base layer, the mass fraction of the individual hydrometeor classes remain at almost constant values for all three height levels (Fig. 5c, e, $\mathrm{g}$ ), while the CG lightning frequency is ranging between 5 and $25 \mathrm{~min}^{-1}$.

In the early mature stage, the total mass and the mass of the hydrometeor classes remain almost constant in the base layer (Fig. 5d). The sudden increase of the mass for the last observation points is accompanied by an enhancement in the CG lightning frequency. The rapid increase of the lightning activity with the growing mass is also a dominant effect for the first part of the observations in the mid-level (Fig. 5f). However, this is followed by a still strong increase in the total mass with little changes in the CG lightning activity, while at the end of the observations, the CG flash frequency even decreases with growing mass. The same behavior can be identified in the top-level (Fig. 5h), where the CG lightning frequency is further decreasing with increasing total mass. No conclusive correlations can be drawn from the observations regarding the mass distribution in the squall line and the lightning activity.

\subsection{July 1998: supercell storm and intracloud lightning}

On 21 July 1998, a supercell was forming approximately $80 \mathrm{~km}$ west-south-west of the radar at 1625 UTC. The development of this storm is well described in Fehr et al. (2004). A detailed analysis of the ITF observations and the storm microphysics was presented by Dotzek et al. (2001). The lateral extent of the supercell is much smaller than for the multicell described above (Fig. 3b). However, this cell was by far more intense, with a 

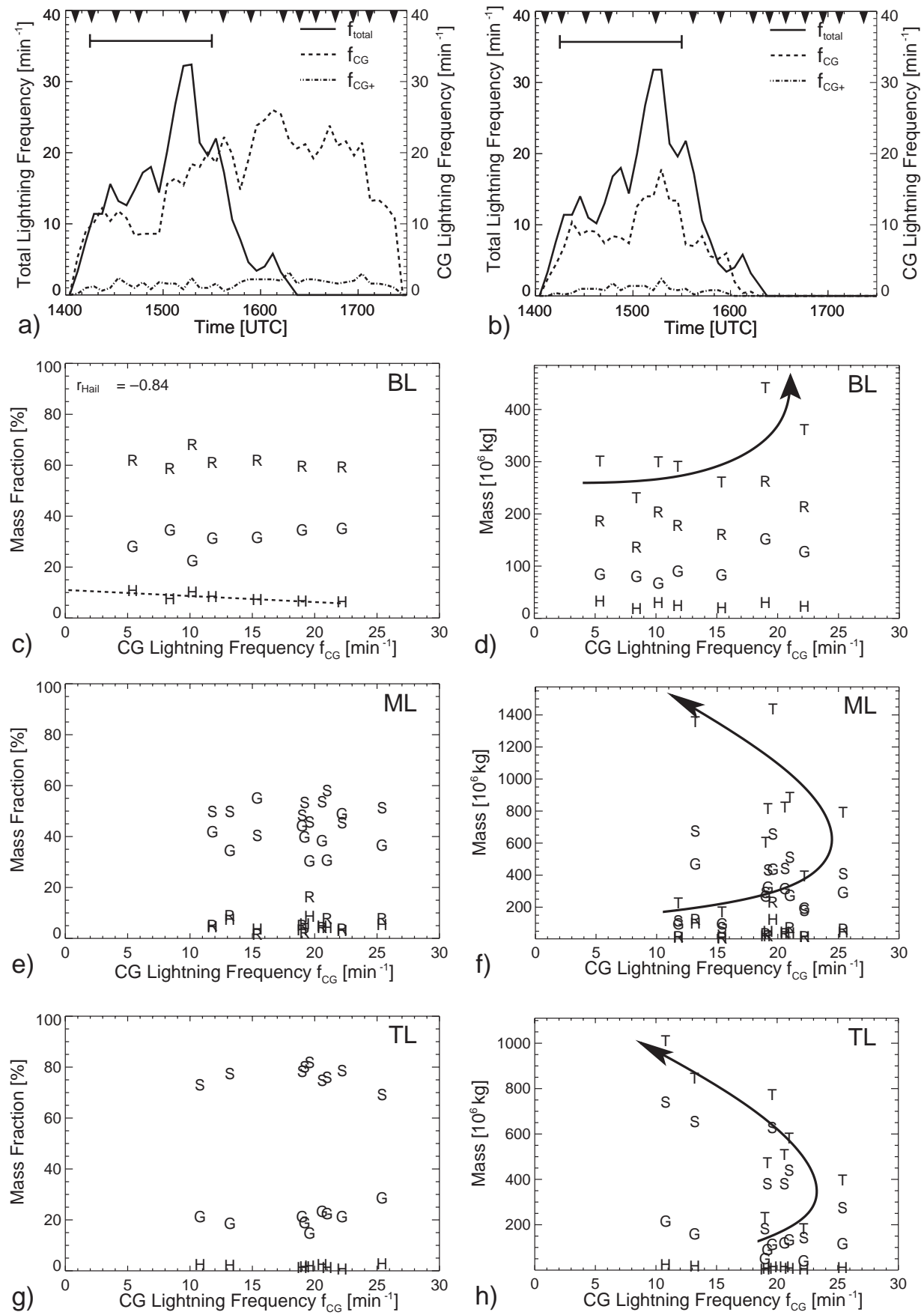

Fig. 5. Lightning and masses for the squall line: (a), (c)-(h) same as Fig. 4. The arrows in (d), (f), and (h) indicate the temporal sequence of radar volume scans. (b) IC and CG lightning frequency restricted to flashes in the ITF lobes (Fig. 1). 
sustained high reflectivity core, reported hail, strong straight-line winds, and a high lightning density.

The thunderstorm entered the ITF area at 1700 UTC and was completely within the range of the system from 1715 UTC on, where it remained until the supercell decayed. The total lightning activity of the storm was dominated by a fourfold increase in the number of flashes within $20 \mathrm{~min}$ starting at $1730 \mathrm{UTC}$ to $47 \mathrm{~min}^{-1}$ (Fig. 6a). Williams et al. (2000) showed that severe weather on the ground is often correlated with such "jumps" in lightning activity and, in fact, there are damage reports for this storm indicating destructive wind speeds, hail, and heavy rain (source: NatCat database, Munich Re). Before this burst, the lightning frequency increased slowly to $10 \mathrm{~min}^{-1}$, and after reaching the maximum, the total activity dropped to approximately $20 \mathrm{~min}^{-1}$. It remained at this level until the electrical activity decayed rapidly at 1905 UTC. The CG lightning frequency on the other hand remained low during the complete life cycle of the storm with two isolated peaks reaching 3.8 and $3.6 \mathrm{~min}^{-1}$ in the developing stage. The total number of flashes as observed by the ITF is 3300, while only 330 flashes were registered by the BLIDS, showing that CG lightning is only a minor contribution to the total electrical activity (Fig. $6 \mathrm{~b})$. It is remarkable that $70 \%$ of the $\mathrm{CG}$ flashes following the maximum in the total lightning activity at 1745 UTC were positive. The study is focusing on IC lightning which clearly dominated the electrical activity of the supercell and is approximated here as the difference between the total lightning activity observed by the ITF and the number of CG lightning from the BLIDS system.

The radar observations cover the complete life cycle of the storm which lasted approximately $3.5 \mathrm{~h}$ resulting in a total of 10 volume scans which are evenly distributed over time. Unfortunately, between 1800 and 1845 UTC the storm track was close to the radar and the volume can only be analyzed up to a height level of approximately $7 \mathrm{~km}$, which reduces the number of volume scans for the upper level region. From 1830 to 1845 UTC the thunderstorm core was only about $15 \mathrm{~km}$ from the radar, therefore only the base level is reasonably covered by the volume scans.

During the developing stage and the maturity of the storm, the mass fraction of rain and graupel remains at an almost constant level around 75\% and 20\%, respectively (Fig. 6c). Therefore, no dependence of the IC lightning activity with the mass fractions can be identified. Only for the last scan during the decaying phase with a low IC flash frequency of less than $2 \mathrm{~min}^{-1}$, the mass fraction of graupel increases significantly, while the rain fraction decreases. The analysis for the total mass in the base layer leads to similar conclusions (Fig. 6d). With the exception of the last scan, the mass of rain and graupel, and with it the total mass do not vary significantly over the storm observation.

There is also no dependence of the lightning activity on the graupel fraction in the midlevel (Fig. 6e), which remains at about 55\%. On the other hand, the data indicates that the IC flash frequency increases with a decreasing snow fraction. Although only being a minor contribution of $5-15 \%$, there exists a positive correlation of lightning with the rain mass fraction, resulting in a linear correlation coefficient of 0.87 . The correlation of the hail mass fraction and IC lightning activity during the lifetime of the storm is forming a distinctive "cycle" that can be separated into three parts: (1) in the developing period, lightning activity is rapidly increasing up to its maximum with an almost constant hail fraction, (2) during the mature stage, the lightning activity decreases with an increasing 

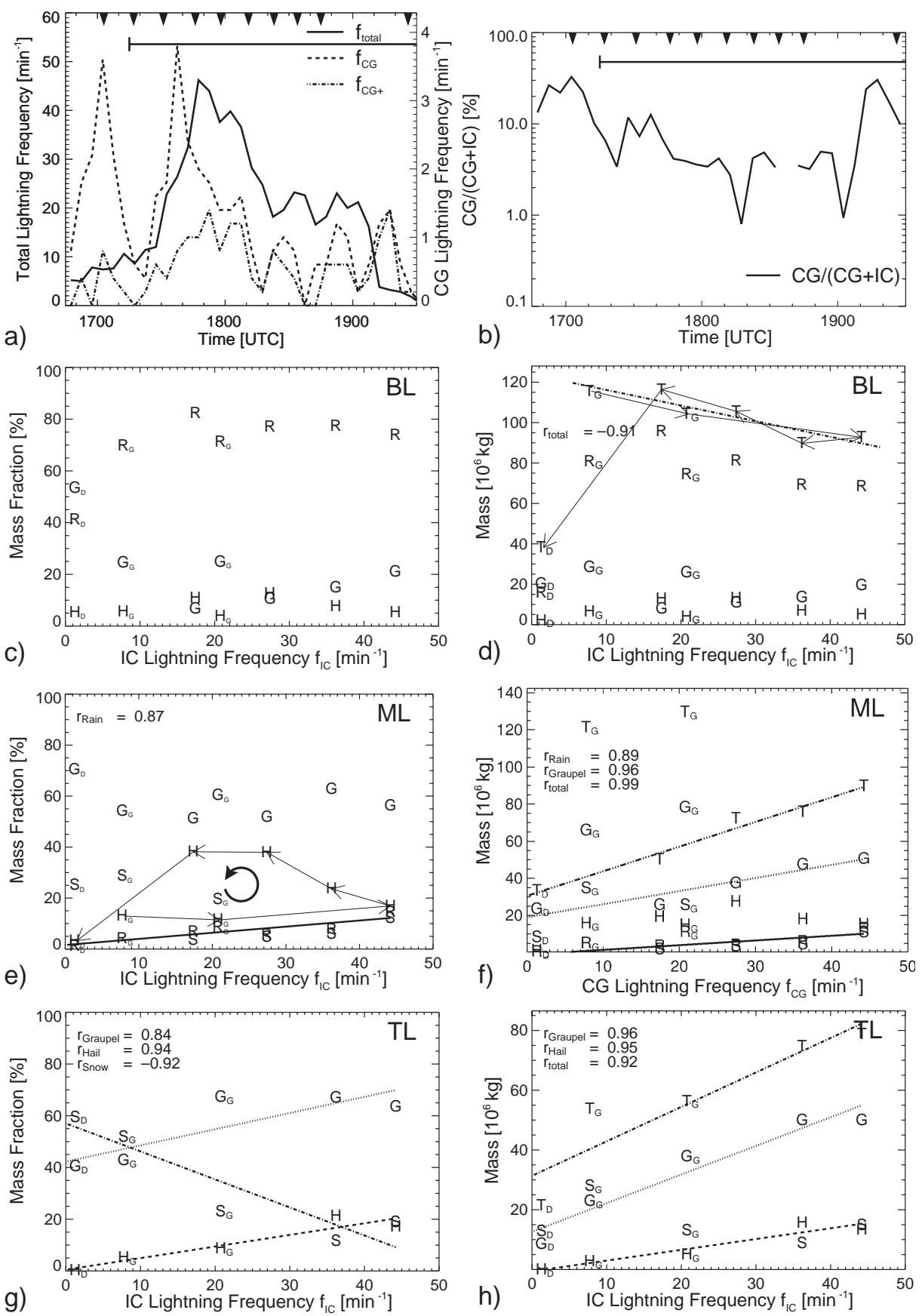

Fig. 6. Lightning and masses for the supercell: (a), (c)-(h) same as Fig. 4, the subscripts "G" and "D" indicate scans during the developing (growing) and decaying storm phase, respectively. (b) The relative amount of CG flashes to the total lightning activity. 
hail fraction, and (3) the decaying stage is characterized by both a decreasing lightning frequency and hail fraction. Although the total mass of hail does not show this distinctive "cycle", a pronounced maximum can be identified for a IC lightning frequency of 27.5 $\min ^{-1}$ (Fig. 6e). Excluding the scans for the developing stage, good linear correlations between the IC flash frequency and the total mass, the mass of graupel, and, to a lesser extent, the mass of rain can be established:

$$
\begin{aligned}
& f_{\mathrm{IC}}=0.75 \times 10^{-6} M_{\text {total }}-23\left(r_{\text {total }}=0.99\right), \\
& f_{\mathrm{IC}}=1.4 \times 10^{-6} M_{\text {graupel }}-27\left(r_{\text {graupel }}=0.96\right), \\
& f_{\mathrm{IC}}=4.0 \times 10^{-6} M_{\text {rain }}+4.2\left(r_{\text {rain }}=0.89\right),
\end{aligned}
$$

with $M$ in $\mathrm{kg}$ and $f$ in $\min ^{-1}$.

Reasonable linear correlations exist between the mass fractions and the electrical activity for the top-level region (Fig. 6g). The lightning frequency is growing with increasing graupel and hail, and decreasing snow fractions:

$$
\begin{aligned}
& f_{\mathrm{IC}}=2.2 F_{\text {hail }}-1.0\left(r_{\text {hail }}=0.94\right), \\
& f_{\mathrm{IC}}=-0.92 F_{\text {snow }}-53\left(r_{\text {total }}=0.92\right), \\
& f_{\mathrm{IC}}=1.6 F_{\text {graupel }}-68\left(r_{\text {graupel }}=0.84\right),
\end{aligned}
$$

The mass of graupel and hail, as well as the total mass in the top-level nicely correlate with the IC lightning frequency:

$$
\begin{aligned}
& f_{\mathrm{IC}}=1.0 \times 10^{-6} M_{\text {graupel }}-13\left(r_{\text {graupel }}=0.96\right), \\
& f_{\mathrm{IC}}=2.8 \times 10^{-6} M_{\text {hail }}+1.7\left(r_{\text {hail }}=0.95\right), \\
& f_{\mathrm{IC}}=0.87 \times 10^{-6} M_{\text {total }}-27\left(r_{\text {total }}=0.92\right) .
\end{aligned}
$$

However, it is important to note that only five radar scans can be used for the top-level.

\section{Discussion}

Before going into details on CG and IC lightning related issues, some general discussion related to the observation systems and the method is presented.

The three presented case studies were selected from the EULINOX storms on the basis of data availability, significance, and representativeness. The radar coverage of the storms strongly depends on their relative position with respect to the radar site at Oberpfaffenhofen. Due to the fact that the POLDIRAD elevation angles for the volume scans were between $1^{\circ}$ and a maximum of $20^{\circ}$, the top-level was often not significantly observed during the period where the storms were close to the radar, while for thunderstorms that 
are more than $70 \mathrm{~km}$ away the base layer was not adequately scanned. Therefore the radar coverage of the storm levels changes over time. However, for all selected cases between five and 10 volume scans were available at the different levels during the storm lifetimes.

Lightning was observed by two systems, the BLIDS for CG and the ONERA ITF for IC flash activity. While the BLIDS network covered the complete radar observation area, the ITF system's field of view was restricted to two lobes. The multicell storm as well as the squall line were only partly covered by the ITF during their lifetimes. However, instead of restricting the analysis to the time when parts of the thunderstorms were inside of the lobes, the CG lightning frequency is used to correlate the electrical activity with the storm bulk microphysics. While in case of the squall line there are some indications that the $\mathrm{CG}$ flashes give a fair representation of the actual electrical activity (Fig. 5b), this does not hold for the multicell storm. Therefore, the analysis for the multicell is truly a study of CG lightning activity alone, which does not necessarily correlate to the total activity. This can be seen in the comparison of the total and the CG lightning frequency in Fig. 4a for the period during which parts of the storm were inside the ITF lobes: the pronounced maximum in total lightning was not accompanied by a similar feature in the CG lightning activity.

The use of a C-band polarimetric radar with a wavelength of $5 \mathrm{~cm}$ to study the noninductive electrification process itself in thunderstorms has its limits. Neither the supercooled liquid water droplets necessary for the riming process of graupel, nor small ice crystals of the collision process can be identified directly. However, with the method described above bulk microphysical properties can be derived: the identification of different hydrometeor classes and their mass. Even though error estimates of the approach by Höller et al. (1994) and Höller (1995) are difficult to perform due to lack of verification data, the results are consistent with the model understanding of thunderstorms and trends in the mass development are correctly represented.

The radar-derived mass of the different classes is a function of both the number and size of the particles. For the electrification process this is also an indicator of how frequent collisions between different hydrometeors, in particular with graupel, can take place and of the number of potential charge carriers. A large relative abundance of particles with higher terminal fall velocities that can only be suspended and grow in strong updraft conditions, like hail and graupel, indicate vigorous storm dynamics with strong updrafts. The more their mass contributes to the total mass in the upper levels relative to snow and rain, the stronger the upward transport in the storm.

\subsection{Cloud-to-ground lightning}

The increase of the CG lightning frequency towards the late mature stage of the multicell storm can already be deduced from Fig. 4a. The correlation presented in Fig. 4b shows a very good linear relation between CG lightning frequency and total storm mass that holds during the mature stage, when the mass is still increasing, and for the storm decay with decreasing mass. However, the detailed analysis of the mass fraction and the total mass gives some insight into the processes that underlie this correlation.

The high graupel mass fraction in the top-level (Fig. 4g) during the developing and early mature stage indicates strong updraft dynamics. The CG lightning frequency with 
less than $2 \mathrm{~min}^{-1}$ in this phase, however, remains low. For the complete observation time, graupel mass fraction is linearly anti-correlated with the $\mathrm{CG}$ lightning frequency, indicating a growing CG lightning activity with weakening upward motion. On the other hand, Fig. $4 \mathrm{~h}$ shows the increase of the total mass found in the top-level, which is mainly due to the accumulation of snow, which is very well correlated with an increasing CG lightning frequency. The graupel mass even tends to decrease with growing CG lightning activity. In contrast to particles with higher terminal fall velocities, like graupel and hail, the lighter particles like snow and small graupel can still be transported upward. Thus, the weakening of the storm is compensated by the growth of the storm volume, which almost doubles its total mass during the observation, leading to a higher lightning frequency (Fig. 4b). Note from Fig. 4a, g, and h that the results for the second and third volume scan, where the complete multicell is inside the lobes, indicate that the total lightning activity is growing with increasing mass and mass fraction of graupel in the top layer, while the total mass between the two scans is not changing significantly.

The graupel mass fraction at mid-level does not show an identifiable correlation with the CG lightning frequency and remains between $30 \%$ and $50 \%$ (Fig. 4e). Although constituting only a minor contribution, there is a clear indication that the CG lightning activity is growing with a decrease in hail and rain fraction, pointing to a weakening of the storm. But as in the top-level, the CG lightning activity increases strongly with the snow mass fraction. The overall growth of the system is also reflected by the total mid-level mass (Fig. 4f). The CG lightning activity again shows a good positive linear correlation with the mass. As can be seen from the linear regressions, practically all the mass change during the observation is due to changes in the snow class. The graupel mass does not vary significantly at the mid-level. Since the amount of graupel in the top-level does not change with time, the graupel produced in the mid-level is subsiding to the base layer, which can be identified in the growing mass fraction of graupel (Fig. 4c), as well as in the increase of the total graupel mass (Fig. 4d).

The conclusion from the above is that the CG lightning frequency grows as the updraft velocities are slowly decreasing, leading simultaneously to the following processes: (1) A descending graupel center of gravity and with it a lower charge center. This also explains the high IC lightning activity in the early stage of the storm where the charge center is lifted by the strong updrafts, and (2) a reduced availability of graupel for the charging processes. This effect is however compensated by the overall growth of the system. It is remarkable that $\mathrm{CG}$ lightning frequency follows the changes in the radar derived composition of the storm with no significant time lag as can be seen in Fig. 4b.

The results for the CG lightning activity of the squall line as presented in Fig. 5 draw a completely different picture. Although the base layer is biased towards the developing phase, while the mid- and top-level are more representative for the mature stage of the storm, the mass fractions in all three levels does not change significantly over the storm lifetime (Fig. 5c, e, g). This effect maybe explained by the coexistence of several convective cells at different development stages, leading to a quasistationary state in the storm dynamics as could be expected for a squall line. The radar-derived total mass of the storm as presented for the three levels in Fig. $5 \mathrm{~d}$, $\mathrm{f}$, and $\mathrm{h}$ indicates that the storm is continuously growing. The CG lightning activity on the other hand does not follow this development. In particular the results for the mid- and top-level show that the lightning 
frequency does not change significantly with the mass increase, remaining between 20 and $25 \mathrm{~min}^{-1}$, while the mass in the top-levels grows fourfold and in the mid-level threefold. The last volume scans even indicate that the mass of the storm is still growing significantly while the CG lightning frequency decreases. This cannot be attributed to the growing anvil, since the mass fractions remain unchanged and the result is not modified in the case when only the high reflectivity volume above $20 \mathrm{dBZ}$ is considered for the mass estimates (not shown). Therefore, the radar observations alone are not sufficient to explain this process. While there is a close relation between the total and CG lightning frequency during the early mature phase when a significant part of the squall line was inside the ITF observation area, due to the lack of information on total lightning the same must not be the case for the later observations. Another possible explanation is that the composition of the inflow air does change as the squall line is traveling out of the alpine foreland into the Danube valley. Unfortunately, there are no aircraft observations for the pre-storm boundary layer composition. The analysis shows that for the squall line the lightning activity cannot be parameterized by the bulk microphysical properties derived from the radar.

Fig. 7a summarizes the results for the CG lightning frequency and the total mass from all three storms. Only volume scans are considered that cover the complete height of the convective systems, i.e., all the levels. No distinctive correlation between the total mass and the $\mathrm{CG}$ flash activity can be deduced for the combination of the three storms, indicating that the CG lightning frequency cannot be parameterized by a simple function of the total mass that holds universally for different convective systems.

\subsection{Supercell intracloud lightning}

The supercell storm remains in the ITF field of view for almost its complete lifetime. During this period, the electrical activity as observed by the two lightning detection systems was dominated by IC flashes. Except for two brief maxima in the early stages of the storm, the CG lightning frequency remains below $2 \mathrm{~min}^{-1}$, while the total lightning frequency is between 15 and $40 \mathrm{~min}^{-1}$, with a maximum of $47 \mathrm{~min}^{-1}$ as presented in Fig. 6a (Dotzek et al., 2001; Fehr et al., 2004).
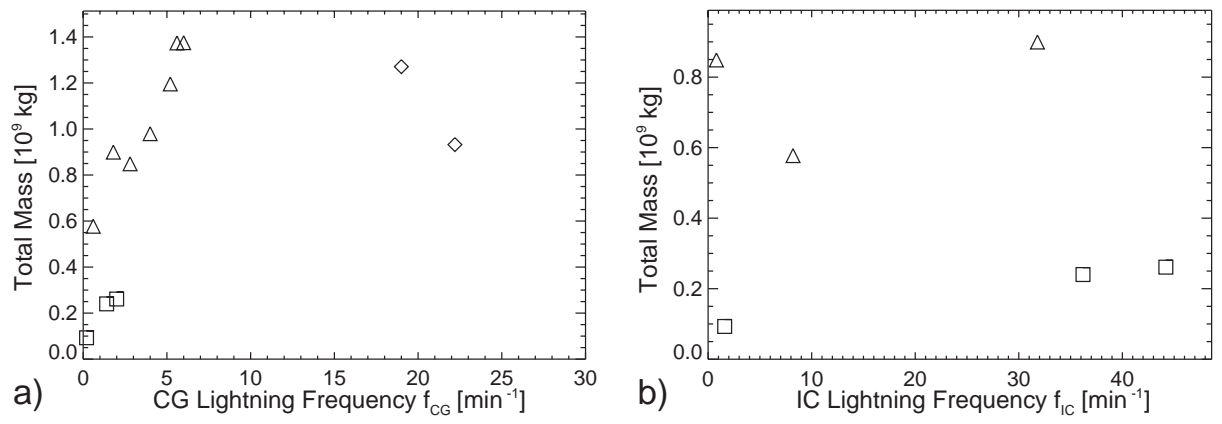

Fig. 7. Lightning activity versus mass for the (a) CG and (b) IC lightning frequency observed for the multicell $(\triangle)$, squall line $(\diamond)$, and the supercell $(\square)$. 
During the early observation period, the supercell develops its characteristics after a storm splitting at around 1645 UTC (e.g., Houze, 1993). The first two volume scans are still significantly influenced by the reorganization of the storm, with two to three convective cells coexisting at the same time. While at the upper level and the base layer this effect is not very pronounced, it does significantly influence the mid-level mass (Fig. 6f). Unfortunately, due to the proximity of the storm during the late mature and decaying phase, only the last scan is representative for this period, and, in fact, reflects the late decaying stage where only little electrical activity was still observed.

The dynamical and bulk microphysical development of the storm and its IC lightning activity can be best seen in the mid- and top-level. The mass fraction (Fig. 6e) at mid-level is characterized by three distinct features: (1) the "cycle" process for the hail fraction, (2) the practically constant amount of graupel, and (3) the well-correlated increase of the IC flash frequency with the rain mass fraction.

The "hail cycle" described in Section 3.3 is a result of the dynamical development of the storm and therefore its charging capabilities. During the developing and early mature stage of the storm, hail is produced at mid-level and transported by strong upward motion into the top-level (Fig. 6g) where it can be supported by strong updrafts, increasing the hail mass fraction. This can be nicely identified in the vertical hail cross section through the storm core during its maturity (Fig. 2f). However, not only the mass fraction of hail is increasing in the top-level, also the graupel mass fraction grows significantly, reducing the relative amount of snow from over $50 \%$ to less than $20 \%$. This rapid upward transport leads to a low hail mass fraction at mid-level. The strong vertical motions as well as the enhanced particle fluxes associated with them efficiently lead to the production of large amounts of charge and high lightning frequencies. During storm maturity, the updrafts are slowly weakening, and with it the charging efficiency, allowing the accumulated hail aloft to descend, increasing the hail fraction. Finally, the further decrease in updraft strength during the decaying phase leads to a final descent of the hail core and a depletion of the hail at mid-level.

The positive correlation of the lightning activity with the fraction of rain in the midlevel of the supercell can be explained as follows: rain aloft is an indictor of strong vertical motion and high liquid water contents associated with effective graupel formation. The presence of rain itself is probably due to recirculation of melted ice particles from regions with lower updraft speeds. The enhanced availability of liquid water droplets could favor an efficient charging through the non-inductive mechanisms due to higher riming potential. The fact that IC lightning is clearly dominating the overall electrical activity for the supercell maturity can be attributed to elevated charge centers due to the strong updrafts. While during this stage the fraction of CG lightning to the total activity remains below $13 \%$, shortly before the last scan in the decaying phase, at around 1915 UTC, CG lightning is contributing more than $30 \%$ for a brief period of $10 \mathrm{~min}$ (Fig. 2b). The last scan is the only radar volume where graupel constitutes a major fraction of the otherwise diminishing thunderstorm mass (Fig. 2c, d). This indicates that as before in the multicell case, the CG lightning activity is growing with the descending graupel core and the charge center associated with it. The fact that practically all CG flashes during the late mature phase and in the final burst are positive can be explained by some observational indications from the interferometer that the supercell was an inverse polarity storm, where 
the mid-level charge center is positive. This supercell is in many respects similar to the predominantly positive CG storms observed during the STEPS project (Lang et al., 2004). Based on the results by Saunders (1993) and Takahashi (1978) high liquid water contents are necessary during the riming of graupel for this process. This hypothesis is supported by the high mass fraction of rain at mid-level.

The processes identified above are only moderately represented in the mass estimates for the hydrometeors. Nevertheless, the IC lightning frequency shows a good linear correlation with the total mass for all three levels during parts of the storm. In particular the positive correlation of IC lightning activity with mass in the mid- and top-level indicate that the electrical activity grows with the overall supply of particles, mainly graupel, that are potential charge carriers (the developing stage in the mid-level is not considered). With the exception of the last volume scan during storm decay, the IC lightning frequency is negatively correlated with the total mass in the base layer. Although this dependence is not very strong, it does obviously show that during the mature stage with high IC lightning activity the updrafts are strong enough to suspend more than $50 \%$ of the total mass above the $0{ }^{\circ} \mathrm{C}$ level, with the strongest precipitation and reduced IC flash frequency in the developing and late mature stage.

As before for the CG lightning activity, Fig. 7b presents all the data where IC flash frequency and total mass of the complete storms is available. Unfortunately, only six radar scans, three each from the multicell and the supercell, can be used. However, already the sparse data indicate that similar to the CG lightning activity, the IC lightning frequency cannot be parameterized by the total mass alone.

\section{Conclusions}

This study investigated three storm types that significantly differed with respect to their microphysical and electrical development. The aim was to find simple relationships that will help develop and improve parameterizations of the lightning activity for the use in mesoscale models or nowcast routines. Mass fractions and total mass contents for the hydrometeor classes derived from polarimetric radar observations are used as measures of the dynamical and bulk microphysical properties of storms, while total and CG lightning activity was monitored by two different lightning detection systems. The major conclusions from this study are:

- The lightning activity can be very different for a similar total mass in different storm, ruling out a universal lightning parameterization based on total mass alone.

- For the isolated thunderstorms investigated the total mass as well as the mass in the individual height levels can be linearly correlated with the IC (supercell) and CG (multicell) lightning activity for distinct stages of the storm. For large organized systems with many coexisting convective cells, as in the case of the squall line, no such dependence can be established.

- There appears to be only a small or no time lag between changes in the upper storm bulk microphysics and electrical activity, indicating that the lightning activity follows closely the dynamical and microphysical development. 
- There are strong indications from the comparison of the storms that the level of convective organization strongly influences the lightning development in a storm which will have to be included in a parameterization of lightning.

- Linear correlations between the radar derived masses and mass fractions and the lightning frequency can be established and related to the non-inductive charging hypothesis. The fact that the correlations between flash rates and mass fractions at different levels could be explained with the non-inductive mechanism is at least circumstantial evidence supporting the importance the non-inductive mechanism in storm electrification.

In order to further quantify the relationship between lightning and bulk micro-physical properties to be used in parameterizations, more convective systems have to be analyzed. New measures for the convective organization or more basic physical processes have to be developed and included into future lightning parameterization.

\section{Acknowledgments}

The authors would like to thank Pierre Laroche and Claire Théry, ONERA, France, for providing the ITF data, and Stephan Thern, Siemens AG, Germany, for the BLIDS data. This work was partly funded by the Commission of the European Communities under contract No. ENV4-CT97-0409.

\section{References}

Allen, D.J., Pickering, K.E., 2002. Evaluation of lightning flash rate parameterizations for use in a global chemical transport model. J. Geophys. Res. 107 (D23), 4711.

Baker, M.B., Christian, H.J., Latham, J., 1995. A computational study of the relationship linking lightning frequency and other thundercloud parameters. Q. J. R. Meteorol. Soc. 121, 1525-1548.

Cummins, K.L., Murphy, M.J., Bardo, E.A., Hiscox, W.L., Pyle, R.B., Pifer, A.E., 1998. A combined TOA/ MDF technology upgrade of the U.S. National Lightning Detection Network. J. Geophys. Res. 103 (D8), 9035-9044 (Apr.).

DeCaria, A.J., Pickering, K.E., Stenchikov, G.L., Scala, J.R., Stith, J.L., Dye, J.E., Ridley, B.A., Laroche, P., 2000. A cloud-scale model study of lightning generated $\mathrm{NO}_{\mathrm{x}}$ in an individual thunderstorm during STERAOA. J. Geophys. Res. 105 (D9), 11601-11616.

Defer, É., 1999. Caracterisation et modélisation de l'activité électrique de nuages d'orage. Note Technique NT1999-6, ONERA.

Defer, E., Blanchet, P., Théry, C., Laroche, P., Dye, J.E., Vinticinque, M., Cummins, K., 2001. Lightning activity for the July 10, 1996, storm during the Stratospheric-Tropospheric Experiment: Radiation, Aerosols, and Ozone-A (STERAO) experiment. J. Geophys. Res. 106 (D10), 10151-10172 (May).

Dotzek, N., Höller, H., Théry, C., Fehr, T., 2001. Lightning evolution related to radar-derived microphysics in the 21 July 1998 EULINOX supercell storm. Atmos. Res. 56, 335-354.

Dye, J.E., Ridley, B.A., Skamarock, W., Barth, M., Venticinque, M., Defer, E., Blanchet, P., Théry, C., Laroche, P., Baumann, K., Hubbler, G., Parish, D.D., Ryerson, T., Trainer, M., Frost, G., Holloway, J.S., Fehsenfeld, F.C., Tuck, A., Matejka, T., Bartels, D., Rutledge, S.A., Lang, T., Stith, J., Zerr, R., 2000. An overview of the Stratospheric-Tropospheric Experiment: Radiation, Aerosols and Ozone (STERAO)-Deep Convection experiment with result from the July 10, 1996 storm. J. Geophys. Res. 105 (D8), 10023-10045 (Apr.). 
Federer, B., Waldvogel, A., 1975. Hail and raindrop size distribution from a Swiss multicell storm. J. Appl. Meteorol. 14, 91-97 (Feb.).

Fehr, T., 2000. Mesoskalige Modellierung der Produktion und des dreidimensionalen Transports von Stickoxiden in Gewittern. Forschungsbericht 2000-21, Deutsches Zentrum für Luft-und Raumfahrt, Porz-WahnheideLinder Höhe, D-51170 Köln.

Fehr, T., Höller, H., Huntrieser, H., 2004. Model study on production and transport of lightning produced $\mathrm{NO}_{\mathrm{x}}$ in a EULINOX supercell storm. J. Geophys. Res. 109 (D09102) (May).

Höller, H., 1995. Radar-derived mass-concentrations of hydrometeors for cloud model retrievals. 27th Conf. on Radar Meteorology, Vail, CO, pp. 453-454 (Oct.).

Höller, H., Schumann, U. (Eds.), 2000. EULINOX - The European Lightning Nitrogen Oxides Experiment. Forschungsbericht 2000-28, Deutsches Zentrum für Luft-und Raumfahrt, Porz-Wahnheide. Linder Höhe, D51170, Köln.

Höller, H., Bringi, V.N., Hubbert, J., Hagen, M., Meischner, P.F., 1994. Life cycle and precipitation formation in a hybrid-type hailstorm by polarimetric and Doppler radar measurements. J. Atmos. Sci. 51 (17), 2500-2522 (Sep.).

Houze, R.A., 1993. Cloud dynamics. International Geophysics Series, vol. 53. Academic Press, San Diego, CA. Kurz, C., Grewe, V., 2002. Lightning and thunderstorms: Part I. Observational data and model results. Meteorol. Z. 11 (6), 379-393 (Dec.).

Lang, T., 1997. Relationship between storm structure and lightning activity in Colorado convection observed during STERAO-A. Master's thesis, Colorado State University, 167 pages.

Lang, T.J., Rutledge, S.A., 2002. Relationships between convective storm kinematics, precipitation, and lightning. Mon. Weather Rev. 130, 2492-2506 (Oct.).

Lang, T.J., Miller, L.J., Weisman, M., Rutledge, S.A., Barker, L.J. III, Bringi, V.N., Chandrasekar, V., Detwiler, A., Doesken, N., Helsdon, J., Knight, C., Krehbiel, P., Lyons, W.A., MacGorman, D., Rasmussen, E., Rison, W., Rust, W.D., Thomas, R.J., 2004. The severe thunderstorm electrification and precipitation study. BAMS, $1107-1125$.

MacGorman, D.R., Straka, J.M., Ziegler, C.L., 2001. A lightning paramerterization for numerical cloud models. J. Appl. Meteorol. 40, 459-478 (Mar.).

Mansell, E.R., MacGorman, D.R., Ziegler, C.L., Strake, J.M., 2002. Simulated three-dimensional branched lightning in a numerical thunderstorm model. J. Geophys. Res. 107 (D9) (May).

Marshall, T.C., Rust, W.D., Stolzenburg, M., 1995. Electrical structure and updraft speeds in thunderstorms over the southern Great Plains. J. Geophys. Res. 100 (D1), $1001-1015$ (Jan.).

Mazur, V., Williams, E., Boldi, R., Maier, L., Proctor, D.E., 1997. Initial comparison of lightning mapping with operational Time-Of-Arrival and Interferometric systems. J. Geophys. Res. 102 (D10), 11071-11085.

Molinié, G., Pinty, J.-P., Roux, F., 2002. Some microphysical and electrical aspects of a cloud resolving model: description and thunderstorm case study. C. R. Phys. 3 (10), 1305-1324.

Pickering, K.E., Wang, Y., Tao, W.-K., Price, C., Müller, J.-F., 1998. Vertical distribution of lightning $\mathrm{NO}_{\mathrm{x}}$ for the use in regional and global chemical transport models. J. Geophys. Res. 103 (D23), 31203-31216 (Dec.).

Price, C., Rind, D., 1992. A simple lightning parameterization for calculating global lightning distributions. J. Geophys. Res. 97 (D9), 9919-9933 (Jun.).

Price, C., Rind, D., 1993. What determines the cloud-to-ground fraction in thunderstorms? Geophys. Res. Lett. 20 (6), 463-466 (Mar.)

Saunders, C.P.R., 1993. A review of thunderstorm electrification processes. J. Appl. Meteorol. 32, 642-655 (Apr.).

Schroth, A.C., Chandra, M.S., Meischner, P.F., 1988. A C-band coherent polarimetric radar for propagation and cloud physics research. J. Atmos. Ocean. Technol. 5 (6), 803-822.

Sekhon, R.S., Srivastava, R.C., 1971. Doppler radar observations of drop-size distributions in a thunderstorm. J. Atmos. Sci. 28 (6), 983-994 (Sep.).

Stockwell, D.Z., Giannakopoulos, C., Plantevin, P.H., Carver, G.D., Chipperfield, M.P., Law, K.S., Pyle, J.A., Shallcross, D.E., Wang, K.Y., 1999. Modelling $\mathrm{NO}_{\mathrm{x}}$ from lightning and its impact on global chemical fields. Atmos. Environ. 33 (27), 4477-4493. 
Stolzenburg, M., Rust, W.D., Marshall, T.C., 1998. Electrical structure in thunderstorm convective regions 3. Synthesis. J. Geophys. Res. 103 (D12), 14097-14108 (Jun.).

Straka, J.M., Zrnic, D.S., Ryzhkov, A.V., 2000. Bulk hydrometeor classification and quantification using polarimetric radar data: synthesis of relations. J. Appl. Meteorol. 39 (8), 1341-1372 (Aug.).

Takahashi, T., 1978. Riming electrification as a charge generation mechanism in thunderstorms. J. Atmos. Sci. 35, $1536-1548$

Théry, C., 2001. Evaluation of LPATS data using VHF interferometric observations of lightning flashes during the EULINOX experiment. Atmos. Res. 56, 397-409.

Williams, E., Rothkin, K., Stevenson, D., Boccippio, D., 2000. Global lightning variations caused by changes in thunderstorm flash rate and by changes in the number of thunderstorms. J. Appl. Meteorol. 39, 2223-2230 (Dec.).

Yagi, T., Uyeda, H., 1980. Different size distributions of snow based on meteorological situations. In: Soulage , R.G. (Ed.), Communications à la VIIIème Conférence International sur la Physique des Nuages, vol. I, pp. 231-234. 